IP Periodica Polytechnica

Transportation Engineering

46(4), pp. 171-178, 2018

https://doi.org/10.3311/PPtr.9410

Creative Commons Attribution (i)

\title{
Urban Planning: a Game Theory Application for the Travel Demand Management
}

\author{
Mark Koryagin ${ }^{1 *}$
}

Received 16 August 2016; accepted 24 October 2016

\begin{abstract}
Urban infrastructure in the developing nations is generating a great number of environmental problems. Therefore, the problem of land distribution among road networks, parking spaces and landscaped parks is to be researched. The passenger behavior depends on traffic congestion, parking search time, public transport frequency, parking fee, etc. The travel mode choice model is described by logit function.

A city territory is subdivided into three districts, residential, central and industrial, each of them trying to develop and implement the optimal policy of land use. The district criterion includes residential travel times, congestion and impacts of the parks on the environment. Any district should solve the effective land use problem while the public transport system tries to find the optimal frequency.

The travel time depends on road capacity and is described by Greenshields model. The influence of parking capacity upon the parking search time is described by the BPR formula.

Participants' solutions influence one another; therefore, the coalition-free game is constructed. The existence of Nash equilibrium is proved for districts, passengers and public transport. The numerical example shows the impacts of value of time (VOT), population density and parking fee rates on districts land use.
\end{abstract}

\section{Keywords}

land use, parking, urban transportation, public transportation, mode choice, environmental impacts, mathematical models, Nash equilibrium

\footnotetext{
${ }^{1}$ Laboratory of Modeling of Social, Economic and Industrial Systems, Kemerovo State Agricultural Institute, 650056 Kemerovo, Markovtsev St., 5, Russia

${ }^{*}$ Corresponding author, e-mail: markkoryagin@yandex.ru
}

\section{Introduction}

The urban transport system optimization has been one of the most important socio-economic and environmental problems in recent decades. The problem complexity arises from the fact that the transportation process is associated with many issues affecting major society spheres. The most important issue is the mutual influence between the passengers' choice of the transport strategy and changes in the urban transport system.

Currently the fundamental goal of many studies is the search of sustainable development models for cities, in particular, the models of citizens' sustainable mobility. Vuchic (Vuchic, 1999) distinguishes four levels of transport planning where the first level describes the relationship between the city (agglomeration) and the transport system: it is interaction of the transport system with all other aspects of the city (economy, ecology, resettlement and housing, social processes, etc.). Land use and transport planning are not easy to integrate since each of them use too different tools, instruments, indicators of planners (Te Brömmelstroet and Bertolini, 2008), which is why integration of transport and land use plan making is still very limited in practice (Bertolini et al., 2005). The land use transport (LUT) visions significantly reduce the chances of conflicting land use and transport plans (Te Brömmelstroet and Bertolini, 2008).

But in general, the problem solution depends on the professionalism of the planners who use simulation modelling tools and local optimization models. Sometimes the planners make wrong decisions, which only aggravate the situation, because they are unable to take into account passengers' travel behavior that may lead to paradoxical results. Braess's paradox (Braess, 1969; Ding et al., 2008) states that adding extra capacity to a road network may reduce overall performance. This is because the Nash equilibrium for such systems is not necessarily optimal. The Downs-Thompson paradox (Downs, 2004; Ding et al., 2008) states that in the presence of public transport increasing the capacity of public roads does not improve but, on the contrary, deteriorates road conditions. The Lewis-Mogridge position (Mogridge, 1990) is based on the observation that the more roads are built, then 
more traffic there is to fill these roads. Therefore, at present the urban planning process requires reducing the land paved for car infrastructure (Litman, 2011).

The road congestion research started almost a hundred years ago (Greenshields, 1935) and the problem still remains. Numerous researchers have been studying the parking management problems. However, the paradoxical results of the research relate not only to roads but also to parking lots. Shoup (Shoup, 1997) stated that the authorities' subsidy for free parking at work triples the vehicle operating cost for driving to work. The review (Hollander et al., 2006) describes several models of parking management that require reducing parking space to zero. The parking policy measures have become more important than many other traffic management measures for reducing car traffic (Litman, 2013; Rye, 2010).

The developing countries face acute transportation problems which are based on the increasing rate of car ownership (Khovavko, 2014; Szendro and Torok, 2014). The infrastructure is not developing so fast - usually the land assigned to roads is less than $10 \%$ against $20-35 \%$ in the developed countries (Cervero, 2013). The cities are urgently required to realize transport strategies (World Bank, 2011) for decreasing negative impacts of transportation on the environment (Demirel et al., 2008).

\section{Models of urban passenger transportation system}

Analytical models would allow solving complex problems of travel demand management in real time, which is impossible in the existing simulation models. The analytical models will become an important tool for solving problems of urban transport systems development taking into account social, economic and environmental impacts. The classes of mathematical models describing the quality of life, urban transport system, the passenger decision making and tasks of municipal regulation of the transport system are being developed.

An urban transport system is managed by the authorities, passengers and different companies that can change travel behaviour. Therefore, transport scientists use game theory to describe different interests of the urban transport system participants.

Simplified models, e.g. the model of travel route choice used in Braess's model (Ding et al., 2008), describe interest conflicts only among passengers. The travel mode choice (car, railway, park\&ride) was described in (Liu et al., 2009). The combination of travel route and parking choice was presented in (Balijepalli et al., 2008). Departure times choice allows avoiding traffic jams and choosing the best parking lot (Zhang et al., 2008).

Multiplayers game models describe conflicts between the government and the travellers. The parking fees optimisation (Zong et al., 2015; Zhang et al., 2008) makes it possible to manage travellers' parking choice. In (Basso and Silva, 2014) the optimization of parking space influencing travel mode choice was described, but the models didn't consider the influence of the mode choice upon travel time (congestion). The models (Takayama and Kuwahara, 2016) allow optimizing parking and bottleneck capacities, parking fees for finding a social optimum.

The land use planning (Anas and Kim, 1996) describes the equilibrium in the land market (distribution of employment, shopping areas and roads) with road congestion taken into account.

\section{Statement of the problem}

Let's consider a city model consisting of three districts, which are located on the same line. The territory of each district is split among residential areas, commercial and industrial complexes and the civic centre.

But these areas do not occupy all the territory (Fig. 1), the remaining space is used for transportation networks (roads and parking spaces) and landscaped parks (environment).

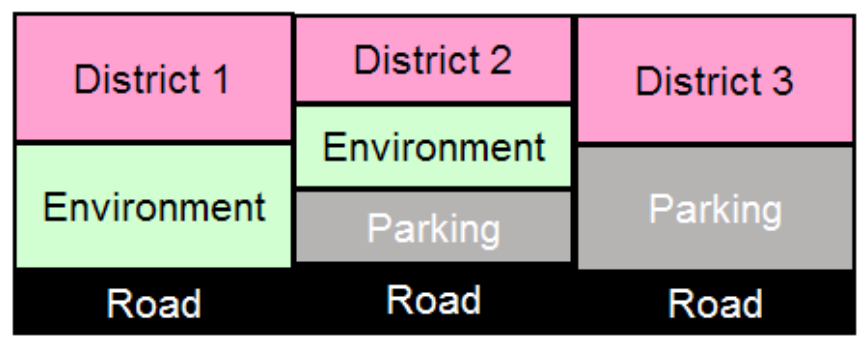

Fig. 1 The land use model for the one-dimential city

When the traffic is fixed, the population benefits from the increase of roads capacity, parking space and environmental areas (Fig. 1). E.g., increase of the road width reduces the risks of traffic congestion, diminishes the travel time and decreases vehicle exhaust gas emission. The difficulty lies in the fact that the district area is limited and it is not possible to enlarge the spaces for parking, roads and environment simultaneously.

Therefore, the problem of rational land use planning is an extremely complicated one for most cities. The statement of the problem considered in this article enables finding the equilibrium distribution of the district land, since finding the optimal solution for all cities is almost impossible due to the non-convex dependency and the large number of variables in a real sized city.

The city model includes residential, central and industrial districts. Residential district 1 doesn't have a parking space due to the absence of a working area. Industrial district 3 has no need of additional recreational areas. Extended central business district 2 consists of residential, shopping and working areas.

The origin-destination matrix is fixed, and thus the presented model is simplified, i.e. the problems of trip generation and trip distribution are not considered. Nevertheless, each passenger flow will split into a transit mode and a car mode. The flows inside each district are not included into the model as the district facilities are located within walking distance. 
Also only morning commuters from residential areas (District 1,2) to working areas (Districts 2, 3) are considered. Consequently, we have only 3 passenger flows (Fig. 2), each of them trying to find an optimal proportion of a transit mode and a car mode.

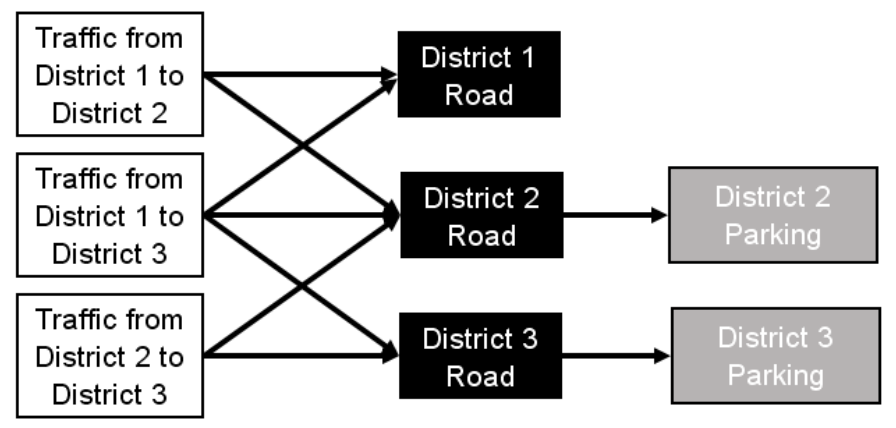

Fig. 2 Linkage of traffic flows between districts with parking spaces and road network

The problem of land use is specified individually for each district. The district should allocate the land to green spaces, parking lots and roads in order to find the best way to meet the needs of the district population.

The public transport also must satisfy the requirements of passengers to transit mode.

All the above-mentioned three types of participants (3 passenger flows, 3 districts and public transport) form a model; therefore, the game-theoretic model with 7 players will be described in the next part of the article.

\section{Mathematical model}

We introduce some basic parameters, most of which relate to district $i$ : $s_{i}^{r}$ land for roads; $s_{i}^{p}$ land for parking; $s_{i}^{e}$ land for landscaped parks. The district land for such objects is limited by $s_{i}$, therefore, the inequality constraint arises

$$
s_{i}^{r}+s_{i}^{p}+s_{i}^{e} \leq s_{i}
$$

The parameter $\lambda_{i, j}$ presents flow of the movements by public and private transport from district $i$ to district $j$. The probability of using a car for a trip between districts is $p_{i, j}$; hence, the probability of using public transport is $1-p_{i, j}$.

Thus the car traffic in district $i\left(\Lambda_{i}\right)$ :

$$
\begin{gathered}
\Lambda_{1}=\lambda_{1,2} p_{1,2}+\lambda_{1,3} p_{1,3}+\lambda_{2,1} p_{2,1}+\lambda_{3,1} p_{3,1}, \\
\Lambda_{2}=\sum_{\substack{i, j=1 \\
i \neq j}}^{3} \lambda_{i, j} p_{i, j}, \\
\Lambda_{3}=\lambda_{2,3} p_{2,3}+\lambda_{1,3} p_{1,3}+\lambda_{3,2} p_{3,2}+\lambda_{3,1} p_{3,1} .
\end{gathered}
$$

All traffic moves through district 2 (3). The amount of occupied parking lots for each district $i\left(P_{i}\right)$

$$
P_{i}=\sum_{\substack{j=1 \\ j \neq i}}^{3} \lambda_{j, i} p_{j, i}, i=1,2,3 .
$$

The time - spending functions in each district $i$ are: $T_{i}^{p}\left(s_{i}^{p}, P_{i}\right)$ - search time in a car park, which depends on the parking capacity and car traffic, i.e. the number of cars to which the given district is assigned as a destination point (occupied land); $T_{i}^{r}\left(s_{i}^{r}, \Lambda_{i}\right)$ the driving time, which depends on the road width and traffic; $T_{i}^{t}\left(s_{i}^{r}, \Lambda_{i}\right)$ the travel time if using public transport (without the variable of waiting time $t_{w}$ ).

Traffic congestion influences travel time by transit mode if public transport uses public roads. The using of dedicated bus lanes significantly reduces the impact of $s_{i}^{r}$ and $\Lambda_{i}$. The transit fare is denoted as $c^{t}$.

The integral cost function of car travel between the districts depends on the travel time. E.g., the integral cost for car travel from district 1 to district 2

$$
C_{1,2}^{r}=c^{c}\left(T_{1}^{r}+T_{2}^{r}+T_{2}^{p}\right)+c_{2}^{p},
$$

where $c^{c}$ is average value of time and $c_{j}^{p}$ is parking fee.

Describing the influence of traffic upon environment we should take into account various parameters, such as the effect of transportation on soil, air (including noise), water course, but first and foremost, the residents' health and comfort of life, the last two parameters should be expressed monetary. The environmental damage, first of all, the impact of traffic upon the people's health, most of all depends on car travel time (including both parking and driving): the longer travel time gets (due to traffic congestion), the more serious damage is caused. The environmental damage parameter is $D$ per one engine hour. Positive influence on the residents' health is exerted by landscaped parks; the parameter of environment improvement is $E$ per the parks square. Evaluation of the environmental parameters $(D$ and $E$ ) is a complicated problem which is not supposed to be solved in this article.

Thus environmental improvement (minus means damage) for district 1 is

$$
\begin{aligned}
E s_{1}^{e}-D T_{1}^{r} & \left(\lambda_{1,2} p_{1,2}+\lambda_{1,3} p_{1,3}+\lambda_{2,1} p_{2,1}+\lambda_{3,1} p_{3,1}\right) \\
& -D T_{2}^{p}\left(\lambda_{2,1} p_{2,1}+\lambda_{3,1} p_{3,1}\right) .
\end{aligned}
$$

\subsection{Passenger decision making}

The travel mode choice is an important step of the transportation forecasting (Litman, 2011). A private car and public transport are the main travel modes for a long-distance travel.

The passenger flows try to find an optimal proportion between using a private car and public transport. In the developing nations low income residents prefer to use public transport (cars allow reducing the travel time while the travel cost increases). The travellers' value of time was presented by exponential (Koryagin, 2015) or uniform (Dodgson and Katsoulacos, 1988) distribution, though usually for travel mode choice the logit 
functions are used, which allow taking into account particular qualities of passengers (Hollander et al., 2006; Koryagin and Dekina, 2014; Bravo et al., 2009).

The presented logit function computes the probability of car mode choice, which depends on the difference between the travel time $\Delta t$ and the travel costs $\Delta c$ :

$$
p^{*}(\Delta t, \Delta c)=\frac{1}{1+\exp \left(a_{0}+a_{t} c^{c} \Delta t+a_{c} \Delta c\right)} .
$$

The objective function based on logit function may be presented in the following equation (Hollander et al., 2006; Koryagin and Dekina, 2014):

$$
\begin{aligned}
G(p) & =\left(p-p^{*}(\Delta t, \Delta c)\right)^{2} \\
& =\left(p-\frac{1}{1+\exp \left(a_{0}+a_{t} \Delta t+a_{c} c^{c} \Delta c\right)}\right)^{2} \rightarrow \min _{p} .
\end{aligned}
$$

Claim 1. Function $G(p)$ is convex downward in the parameter $p$.

Proof. The second derivative of (9) is as follows:

$$
G^{\prime \prime}(p)=2 p \geq 0 \text {. QED }
$$

The difference of the travel times between modes (private and public transport) for travelling between districts 1 and 2

$$
\Delta t_{1,2}=T_{1}^{r}+T_{2}^{r}+T_{2}^{p}-T_{1}^{t}-T_{2}^{t}-t_{w},
$$

where $t_{w}$ - public transport waiting time.

The difference between the travel costs would be

$$
\Delta c_{1,2}=c^{c}\left(t_{1}^{r}+t_{2}^{r}+t_{2}^{p}\right)+c_{2}^{p}-c^{t} .
$$

\subsection{Search time in a car park}

Travel time depends on road and car park capacity. Usually the time is described by the standard Bureau of Public Roads (BPR) function (Balijepalli et al., 2008)

$$
t=t^{0}+\alpha\left(\frac{q}{q_{\max }}\right)^{\beta}
$$

where $t^{0}$ is minimal search time in a car park (for a free park), $q_{\max }$ - parking capacity (number of lots), $q$ - the number of currently occupied lots, $\alpha$ and $\beta$ are nonnegative parameters.

The different parking conditions in each district $i$ depend on the parking size and form

$$
T_{i}^{p}\left(s_{i}^{p}\right)=t_{i}^{0}+\alpha_{i}\left(\frac{\gamma_{i} P_{i}}{s_{i}^{p}}\right)^{\beta_{i}}
$$

where $\gamma_{i}$ is the average square of a parking lot.

Claim 2. Function $T_{i}^{p}\left(S_{i}^{p}\right)$ is convex downward in the parameter $S_{i}^{p}$.

Proof. The second derivative of $T_{i}^{p}\left(S_{i}^{p}\right)$ is as follows:

$$
\alpha_{i} \beta_{i}\left(\beta_{i}+1\right) \frac{\left(\gamma_{i} P\right)^{\beta_{i}}}{\left(s_{i}^{p}\right)^{\beta_{i}+2}} \geq 0 \text {. QED }
$$

\subsection{Driving time}

Researchers prefer to use the simplest submodels for constructing a huge model. Usually the travel time (or speed) is described by BPR style function (Balijepalli et al., 2008; Basso and Silva, 2014; Bravo et al., 2009) or Greenberg's model (Greenberg, 1959). The travel time in these models depends on ratio of traffic density to road capacity.

In the present article the classical Greenshields formula (Greenshields, 1935) is used which is a particular case of Greenberg's model. In its classic form, the model describes the dependency between the flow speed and the traffic density. However, it is easy to obtain the dependency between travel times and traffic flows (Koryagin, 2015).

$$
t=\frac{2 L}{v_{0}+\sqrt{v_{0}^{2}-\frac{4 v_{0} \lambda}{\rho_{j}}}}
$$

where $L$ is the length of a road section, $v_{0}$ is free speed, $\lambda$ is a traffic flow, $\rho_{j}$ is the road capacity. Therefore, the travel time through the district $i$ will be

$$
T_{i}^{r}\left(s_{i}^{r}\right)=\frac{2 L_{i}}{v_{0}+\sqrt{v_{0}^{2}-\frac{4 \delta v_{0} \Lambda_{i}}{s_{i}^{r}}}}
$$

where $L_{i}$ is the length of a road in district 1 and $\delta$ is the area occupied by a vehicle on the road jammed with traffic.

Claim 3. Function $T_{i}^{r}\left(s_{i}^{r}\right)$ is convex downward in the parameter $s_{i}^{p}$.

Proof. The second derivative of $T_{i}^{r}\left(s_{i}^{r}\right)$ is as follows:

$$
\begin{aligned}
& \frac{\left(s_{i}^{r}\right)^{4}\left(v_{0}+\sqrt{\left.v_{0}^{2}-\frac{4 \delta v_{0} \Lambda_{i}}{s_{i}^{r}}\right)^{3}\left(v_{0}^{2}-\frac{4 \delta v_{0} \Lambda_{i}}{s_{i}^{r}}\right)}\right.}{+\frac{8 L_{i} \delta^{2} v_{0}^{2} \Lambda_{i}^{2}}{\left(s_{i}^{r}\right)^{4}\left(v_{0}+\sqrt{v_{0}^{2}-\frac{4 \delta v_{0} \Lambda_{i}}{s_{i}^{r}}}\right)^{2}\left(v_{0}^{2}-\frac{4 \delta v_{0} \Lambda_{i}}{s_{i}^{r}}\right)^{3 / 2}}}+\frac{8 L_{i} \delta v_{0} \Lambda_{i}}{\left(s_{i}^{r}\right)^{3}\left(v_{0}+\sqrt{v_{0}^{2}-\frac{4 \delta v_{0} \Lambda_{i}}{s_{i}^{r}}}\right)^{2}\left(v_{0}^{2}-\frac{4 \delta v_{0} \Lambda_{i}}{s_{i}^{r}}\right)^{1 / 2}} \geq 0 . \text { QED }
\end{aligned}
$$

\subsection{District policy}

Each district is sensible to the environment condition and residents' travel time $\left(T_{i}\right)$. The total residents' travel time expenditures for district 1 consist of four summands (public transport and car travels from district 1 to district 2 and from district 1 to district 3 ): 


$$
\begin{aligned}
T_{1}\left(s_{1}^{r}\right) & =\left(T_{1}^{t}+T_{2}^{t}+t_{w}\right) \lambda_{1,2}\left(1-p_{1,2}\right) \\
& +\left(T_{1}^{t}+T_{2}^{t}+T_{3}^{t}+t_{w}\right) \lambda_{1,3}\left(1-p_{1,3}\right) \\
& +\left(T_{1}^{r}\left(s_{1}^{r}, \Lambda_{1}\right)+T_{2}^{r}\left(s_{2}^{r}, \Lambda_{2}\right)+T_{2}^{p}\left(s_{2}^{r}, P_{2}\right)\right) \lambda_{1,2} p_{1,2} \\
& +\left(T_{1}^{r}\left(s_{1}^{r}, \Lambda_{1}\right)+T_{2}^{r}\left(s_{2}^{r}, \Lambda_{2}\right)+T_{3}^{r}\left(s_{3}^{r}, \Lambda_{3}\right)+T_{3}^{p}\left(s_{3}^{p}, P_{3}\right)\right) \lambda_{1,3} p_{1,3} .
\end{aligned}
$$

The objective function for district 1 includes the total travel time expenditures, environmental damage from cars and the environmental area

$$
\begin{aligned}
F_{1}\left(s_{1}^{r}\right)= & D\left(\lambda_{1,2} p_{1,2}+\lambda_{1,3} p_{1,3}\right) T_{1}^{r}\left(s_{1}^{r}, \Lambda_{1}\right) \\
& -E\left(s_{1}-s_{1}^{r}\right)+c^{c} T_{1}\left(s_{1}^{r}\right) \rightarrow \min _{s_{1}^{r}}
\end{aligned}
$$

The objective function for district 2 also takes into account parking space:

$$
\begin{aligned}
F_{2}\left(s_{2}^{r}, s_{2}^{p}\right) & =D\left(\lambda_{1,2} p_{1,2}+\lambda_{1,3} p_{1,3}+\lambda_{2,3} p_{2,3}\right) T_{2}^{r}\left(s_{2}^{r}, \Lambda_{2}\right) \\
& +c^{c} T_{2}\left(s_{2}^{r}, s_{2}^{p}\right)+D \lambda_{1,2} p_{1,2} T_{2}^{p}\left(s_{2}^{p}, P_{2}\right)-E\left(s_{2}-s_{2}^{r}-s_{2}^{p}\right) \rightarrow \min _{s_{2}^{r}, s_{2}^{p}} .
\end{aligned}
$$

District 3 doesn't have a residential area, therefore, environmental condition isn't taken into account:

$$
F_{3}\left(s_{3}^{r}, s_{3}^{p}\right)=c^{c} T_{3}\left(s_{3}^{r}, s_{3}^{p}\right) \rightarrow \min _{s_{3}^{r}, s_{3}^{p}}
$$

Claim 4. Function $F_{i}$ is convex downward in the parameters $s_{i}^{r}, s_{i}^{p}$.

Proof. It should be noted that $T_{i}\left(s_{i}^{r}, s_{i}^{p}\right)$ consists of the functions $T_{i}^{r}\left(s_{i}^{r}, \Lambda_{i}\right)$ and $T_{i}^{p}\left(s_{i}^{p}, P_{i}\right)$. Therefore, functions $F_{1}, F_{2}, F_{3}$ consist of a linear part and summands $T_{i}^{r}\left(s_{i}^{r}, \Lambda_{i}\right)$ and $T_{i}^{p}\left(s_{i}^{p}, P_{i}\right)$ with nonnegative factors. The proof of Claim 4 is obvious because of Claims 2 and 3. QED

\subsection{Public transport}

The third type of players is represented by the public transport. Note that it's not a good idea to use profit as a criterion for the public transport because it performs a social function and is supported from the municipal budget. The desire to maximize profit may lead to lower quality of public transport services the notable example of which is the paradox of Downs. Therefore, we will use the total expenditure on public transport and passengers' travel time as a criterion. The public transport strategy is the frequency or average interval, which is equal to 2 average waiting times.

$$
H=c \sum_{i=1}^{3} \sum_{j=i+1}^{3}\left(\sum_{k=i}^{j} T_{k}^{t}+t_{w}\right) \lambda_{i, j}\left(1-p_{i, j}\right)+\frac{a}{2 t_{w}} \rightarrow \min _{t_{w}}
$$

where $a$ is the cost of 1 round trip of public transport.

In this model public transport uses dedicated lanes or ways (e.g., trams). Therefore, congestion doesn't influence the travel time and the transport operator's expenses. That is why using dedicated lanes is often resorted to for reducing the public transport subsidy (Basso and Silva, 2014) and, consequently, the load on the budget.

Claim 5. Function $H$ is convex downward in the parameter $t_{w}$.

Proof. The second derivative of $H$ is as follows:

$$
\frac{a}{t_{w}^{3}} \geq 0 . \text { QED }
$$

If the public transport uses public roads, then the travel time (and therefore, expenses) will be dependent on traffic congestion. Such condition makes the formula more complicated but it serves the convexity of public transport criterion.

\subsection{Game-theoretical problem formulation}

The researchers often use the game theory for solving urban transport problems (Chen and Cheng, 2010). The theory describes mutual influence of transport and land-use (Chang and Mackett, 2005); the relationship between the government, car users and the parking system (Zong et al., 2015); the parking policy as a conflict of interests between the government and the travellers (Hollander et al., 2006); the interaction between the transport operator, passengers and the authorities (Koryagin, 2015).

The game theory will allow considering features of travel demand generation. Thus, the equilibrium between the interests of the population and the capacity of transport infrastructure is found, which will provide an important tool for designing urban transport systems.

Let us introduce some sets of strategies, and first of all, the sets of passenger strategies ( $p_{i, j}$ belongs to the $I_{i, j}=[0,1]$ ). For district 1 the strategy $s_{1}^{r}$ belongs to the $B_{1}=\left|0, s_{1}\right|$. District 3 strategy $s_{3}^{r}$ belongs to the $B_{3}=\left|0, s_{3}\right|$. District 2 has a more complicated set of strategies (triangle)

$$
B_{2}=\left\{\begin{array}{l}
s_{2}^{r} \geq 0 \\
s_{2}^{p} \geq 0 \\
s_{2}^{r}+s_{2}^{p} \leq S_{2}
\end{array} .\right.
$$

The maximal waiting time $\bar{t}$ must be determined by the urban authorities. The minimal rational waiting time (for the maximal passenger flow) is calculated from the solution of (20)

$$
\underline{t}=\sqrt{\frac{a}{2 c^{c} \sum_{i=1}^{3} \sum_{j=i+1}^{3} \lambda_{i, j}}}
$$

Therefore, the public transport strategy $t_{w}$ belongs to the $J=[\underline{t}, \bar{t}]$.

The normal for game statement of the problem is $\left\langle I_{1,2}, I_{1,3}, I_{2,3}, B_{1}, B_{2}, B_{3}, J,-G_{1,2},-G_{1,3},-G_{2,3},-F_{1},-F_{2},-F_{3},-H\right\rangle$.

Proposition 1. The game $\left\langle I_{1,2}, I_{1,3}, I_{2,3}, B_{1}, B_{2}, B_{3}, J,-G_{1,2},-G_{1,3},-G_{2,3},-F_{1},-F_{2},-F_{3},-H\right\rangle$ has Nash equilibrium.

Proof. Consider the conditions of the Nash equilibrium existence theorem (Glicksberg, 1952).

1. Set of players' pure strategies is compact, convex and not empty. 
The condition is obviously performed for sets

$I_{1,2}, I_{1,3}, I_{2,3}, B_{1}, B_{2}, B_{3}, J$.

2. Players payoff functions are quasiconcave in self strategies and continuous.

The functions $-G_{1,2},-G_{1,3},-G_{2,3}$ are quasiconcave through Claim 1. The functions $-F_{1},-F_{2},-F_{3}$ are quasiconcave in accordance with Claim 4 . The functions $-H$ are quasiconcave with respect to Claim 5. QED

The existence of Nash equilibrium allows using the presented model for solution of the urban land use problem, which will be described in the following example.

\section{Numerical example}

The value of basic parameters are: number of trips $\lambda_{1,2}=\lambda_{1,3}=\lambda_{2,3}=20000$; transit tariff $c^{t}=17$; travel time by transit mode $T_{i}^{t}=0.667$; VOT $c^{c}=200$; damage $D=50$ per car hour; environment improvement $E=3000000$ per $\mathrm{km}^{2}$; logit function parameters $a_{0}=-2, a_{t}=0.08, a_{c}=0.2$; BPR function parameters $\alpha_{i}=0.3, \quad \beta_{i}=3$; free speed $v_{0}=40$; road length $L_{i}=4$; road square for a car $\delta=0,000017 \mathrm{~km}^{2}$.

One of the main factors that is changing in the developing countries is the value of time. This model (Fig. 3) shows that as income increases the probability of using a car soars, but at a certain level (the level of developed countries) the use of personal vehicles goes down.

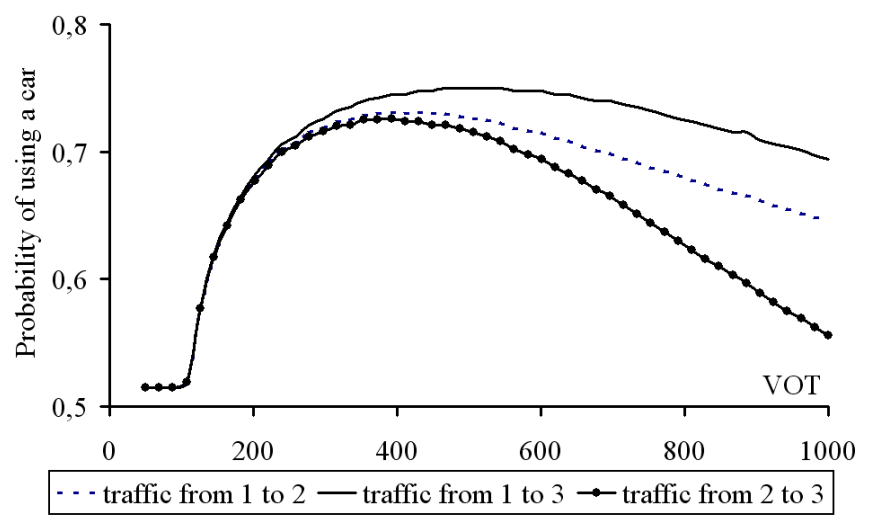

Fig. 3 The influence of VOT on travel mode choice

There is no parking space in the first district. The landscaped area is growing (Fig. 4), but it stabilizes if the VOT exceeds 300 (of course, the situation will change if we take into account the correlation between the VOT and the importance of ecology).

For the second district the situation is similar (Fig. 5), but the transport infrastructure includes not only roads but parking space as well. Note that the area under roads is practically unchanged and roads and parking spaces together occupy a smaller territory than landscaping, although the transport infrastructure quantity is slightly bigger than that of parks.

For the third district the share of roads and parking spaces is virtually equal because the numbers of cars on the roads and in parking lots are identical (Fig. 6).

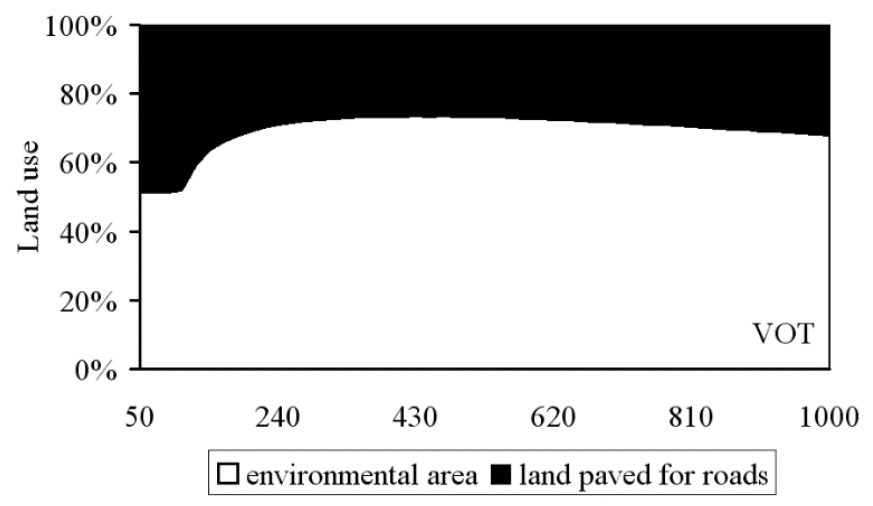

Fig. 4 The influence of VOT on district 1 land-use

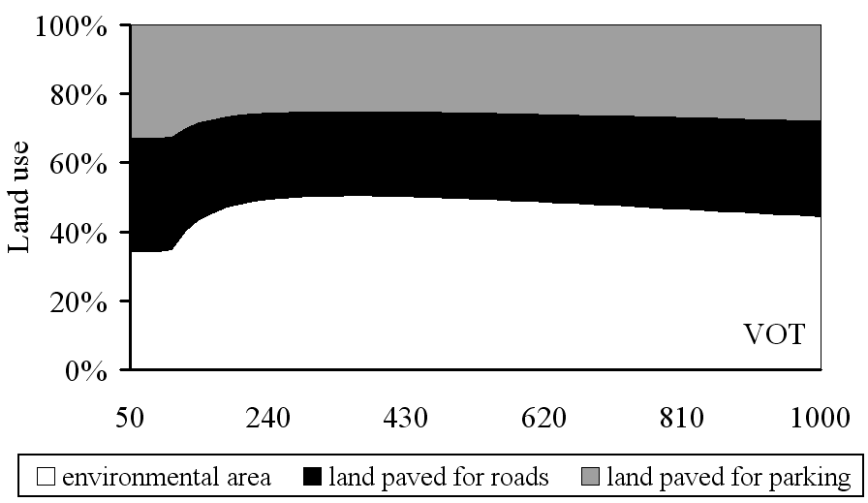

Fig. 5 The influence of VOT on district 2 land-use

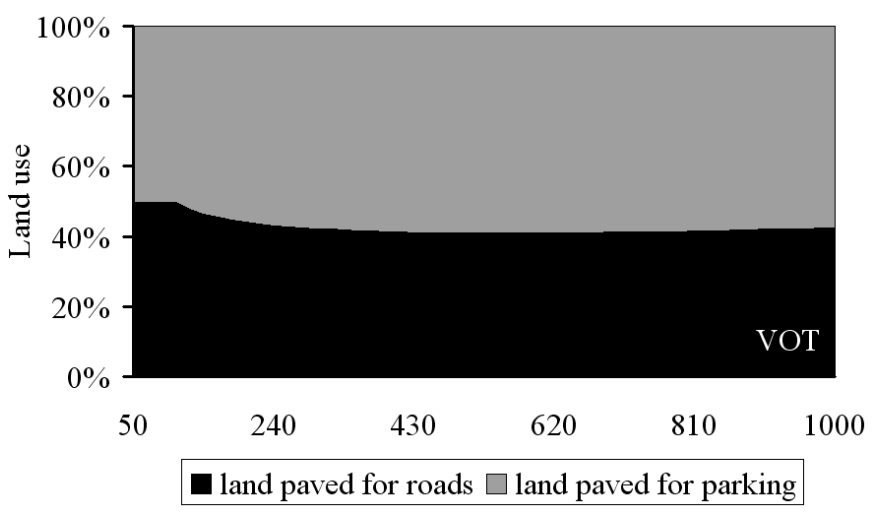

Fig. 6 The influence of VOT on district 3 land-use

It is difficult to compare the three districts because they all use the land differently. It is only possible to compare the area paved for roads which is the largest in district 3 and the smallest in district 2 where congestion is highly likely.

The public transport frequency gradually increases from 15 to 60 because the optimal frequency depends on the VOT (20).

An important parameter of the city is the population density. In this case as the population density correlates with the intensity of passenger flows, we consider this parameter in our study. The passenger flow increases for each O-D pair simultaneously. The growth of population density (Fig. 7) leads to reduction of the landscaping area while the space for roads and parking proportionally increases. 


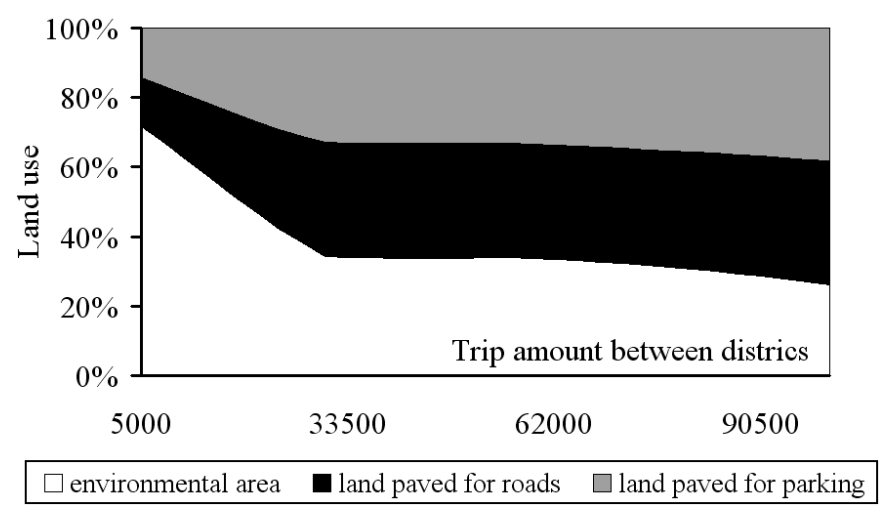

Fig. 7 The influence of population density on district 2 land-use

Another important way to manage the transport system is the introduction of parking fees in order to reduce vehicular flows. Fig. 8 shows that at low fees the area under the transport infrastructure even increases while at high fees the area of landscaping grows and reaches $60 \%$ of the city territory.

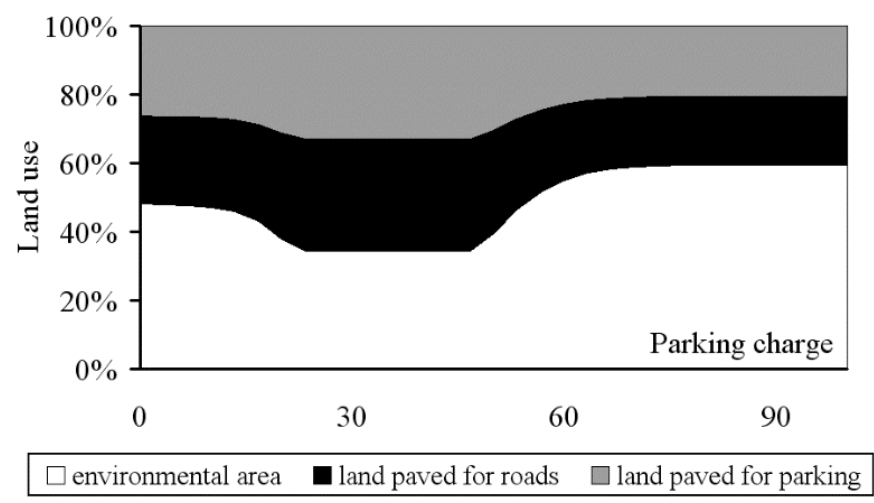

Fig. 8 The influence of parking fees on district 2 land use

Note that the probability of private cars usage is reduced from 70 to $25 \%$. The public transport frequency increases slightly from 25 to 38 and car travel time shrinks by $7 \%$. It should be noted that this model compares the Nash equilibrium for the given parameters. However, not always the local authorities assess the situation adequately and their unsustainable transport policy usually leads to the city degradation.

\section{Conclusions}

The main result of the research is the construction of a mathematical model aimed at rational urban land use. The existence and uniqueness of a solution (Nash equilibrium) allows efficient usage of the model. The numerical example let us recommend that the developing countries should:

- increase green areas;

- reduce the area paved for roads, especially in the urban centre;

- increase the public transport frequency;

- limit the population density;

- increase parking fees.
- The development of the proposed model might be implemented in the following directions:

- generalization of the one-dimensional model for any number of districts;

- generalization in case of the two - dimensional model for rectangular urban patterns, which demands a description of the routes between the two districts through the third one with regard to road intersection. Also it will be necessary to consider the route choice model;

- research of the correlation among the factors (VOT, transit tariff, parking fees, environmental damage and resident's benefits, etc.);

- taking account of trip generation and allocation;

- considering the transit routes network and various types of public transport (with dedicated lines and without them) and tariff optimization;

- considering more travel types (not only morning commutes), including cultural and social ones.

- implementation of the proposed model in a real city.

\section{References}

Anas, A., Kim, I. (1996). General equilibrium models of polycentric urban land use with endogenous congestion and job agglomeration. Journal of Urban Economics. 40, pp. 232-256. https://doi.org/10.1006/juec.1996.0031

Balijepalli, N. C., Shepherd, S. P., May, A. D. (2008). Modelling the choice of car parks in urban areas and managing the demand for parking. In: 87 th Annual meeting of the Transportation Research board, Washington D.C., Jan. 13-17, 2008.

Basso, L. J. Silva, H. E. (2014). Efficiency and substitutability of transit subsidies and other urban transport policies. American Economic Journal: Economic Policy. 6(4), pp. 1-33. https://doi.org/10.1257/pol.6.4.1

Bertolini, L., le Clercq, F., Kapoen, L. (2005). Sustainable accessibility: a conceptual framework to integrate transport and land use plan making. Two test applications in the Netherlands and reflection on the way forward. Transport Policy. 12(3), pp. 207-220. https://doi.org/10.1016/j.tranpol.2005.01.006

Braess, D. (1969). Uber ein Paradoxon aus der Verkehrsplanung. (On a paradox of traffic planning.) Unternehmensforschung. 12(1), pp. 258-268. (in German) https://doi.org/10.1007/BF01918335

Bravo, M., Briceño, L., Cominetti, R., Cortés, C.E., Martínez, F.J. (2009). An integrated behavioral model of the land-use and transport systems with network congestion and location externalities. Transportation Research Part B. 44(4), pp. 584-596. https://doi.org/10.1016/j.trb.2009.08.002

Te Brömmelstroet, M., Bertolini, L. (2008). Developing land use and transport PSS: meaningful information through a dialogue between modelers and planners. Transport Policy. 15(4), pp. 251-259. https://doi.org/10.1016/j.tranpol.2008.06.001

Cervero, R. (2013). Linking urban transport and land use in developing countries. Journal of Transport and land Use. 6(1), pp.7-24 https://doi.org/10.5198/jtlu.v6i1.425

Chang, J. S., Mackett, R. (2005). A bi-level model of the relationship between transport and residential location. Transportation Research Part B. 40(2), pp. 123-146. https://doi.org/10.1016/j.trb.2005.02.002 
Chen, B., Cheng, H. H. (2010). A review of the applications of agent technology in traffic and transportation systems. IEEE Transactions on Intelligent Transportation systems. 11(2), pp. 485-497. https://doi.org/10.1109/TITS.2010.2048313

Demirel, H., Sertel, E., Kaya, S., Seker, D. Z. (2008). Exploring impacts of road transportation on environment: a spatial approach. Desalination. 226(1-3), pp. 279-288.

https://doi.org/10.1016/j.desal.2007.02.111

Ding, C., Song, S., Zhang, Y. (2008). Paradoxes of traffic flow and economics of congestion pricing. UNR Joint economics working paper series. Working paper No. 08-007.

Dodgson, J. S., Katsoulacos Y. (1988). Quality competition in bus services. Journal of Transport Economics and Policy. 22(3), pp. 263-281.

Downs, A. (2004). Stuck in traffic: coping with peak-hour traffic congestion. Brookings Institution Press. Washington.

Glicksberg, I. L. (1952). A further generalization of the Kakutani fixed point theorem, with application to Nash equilibrium. Proceedings of the American Mathematical Society. 3(1), pp. 170-174. https://doi.org/10.2307/2032478

Greenberg, H. (1959). An Analysis of Traffic Flow. Operations Research. 7(1), pp. 79-85 https://doi.org/10.1287/opre.7.1.79

Greenshields, B. D. (1935). A study of traffic capacity. Highway Research Board Proceedings. 14, pp. 448-477.

Hollander, Y., Prashker, J., Mahalel, D. (2006). Determining the Desired Amount of Parking Using Game Theory. Journal of Urban Planning and Development. 132(1), pp. 53-61. https://doi.org/10.1061/(ASCE)0733-9488(2006)132:1(53)

Khovavko, I. (2014). Economic analyses of Moscow traffic jams. E-journal. Public Administration. 43, pp. 121-134. (in Russian)

Koryagin, M. E. (2015). An agent-based model for optimization of road width and public transport frequency. Promet-Traffic\&Transportation. 27(2), pp. 147-153. https://doi.org/10.7307/ptt.v27i2.1559

Koryagin, M .E., Dekina, A. I. (2014). Optimization of the road capacity and the public transportation frequency which are based on logit-model of travel mode choice. Communications in Computer and Information Science. 487, pp. 214-222. 2014 https://doi.org/10.1007/978-3-319-13671-4_26

Liu, T. L., Huang, H. J., Yang, H., Zhang, X. (2009). Continuum modeling of park-and-ride services in a linear monocentric city with deterministic mode choice. Transportation Research Part B. 43(6), pp. 692-707. https://doi.org/10.1016/j.trb.2009.01.001
Litman, T. (2011). Why and how to reduce the amount of land paved for roads and parking facilities. Environmental Practice. 13(1), pp. 38-46. https://doi.org/10.1017/S1466046610000530

Litman, T. (2013). Understanding transport demands and elasticities. How prices and other factors affect travel behavior. Victoria Transport Policy Institute.

Mogridge, M. J. H. (1990). Travel in towns: jam yesterday, jam today and jam tomorrow?. Macmillan Press, London.

Rye, T. (2010). Parking management: a contribution towards livable cities. Module 2c in sustainable transport: A sourcebook for policy - makers in developing cities. GTZ Transport policy service. [Online]. Available from: http://www.sutp.org/files/contents/documents/resources/A_Sourcebook/SB2_Land-Use-Planning-and-Demand-Management/GIZ_SUTP SB2c_Parking-Management_EN.pdf.

Shoup, D. (1997). The high cost of free parking. Journal of Planning education and Research. 17(1), pp. 3-20. https://doi.org/10.1177/0739456X9701700102

Szendrö, G., Török, Á. (2014). Theoretical investigation of environmental development pathways in the road transport sector in the European Region. Transport. 29(1), pp. 12-17. https://doi.org/10.3846/16484142.2014.893538

Takayama, Y., Kuwahara, M. (2016). Scheduling preferences, parking competition, and bottleneck congestion: A model of trip timing and parking location choices by heterogeneous commuters. MPRA Paper. University Library of Munich, Germany. [Online]. Available from: https://mpra.ub.uni-uenchen.de/68938/1/MPRA_paper_68938.pdf.

Vuchic, V. R. (1999). Transportation for livable cities. Center for urban policy research press, Rutgers University, Brunswick, N.J.

World Bank. (2011). Russian Federation - city of St. Petersburg: transport strategy for 2011-2025. World Bank. Washington, DC. [Online]. Available from: http://documents.worldbank.org/curated/en/232341468107660391/ pdf/707690ESW0P1240ort0Strategy007MAR11.pdf.

Zhang, X., Huang, H. J., Zhang, H. M. (2008). Integrated daily commuting patterns and optimal road tolls and parking fees in a linear city. Transportation Research Part B. 42(1), pp. 38-56. https://doi.org/10.1016/j.trb.2007.06.001

Zong, F., He, Y., Yuan, Y. (2015). Dependence of parking pricing on land use and time of day. Sustainability. 7(7), pp. 9587-9607. https://doi.org/10.3390/su7079587 